\title{
Alçando Voo: a Experiência de Ampliar o Diálogo entre Psicologia e Medicina
}

\author{
Soaring to New Heights: the Experience of \\ Expanding the Dialog between Psychology \\ and Medicine
}

\author{
Denise Ribeiro Barreto Mello \\ Ligia Costa Leite \\ Maria das Graças Sepúlveda Campos e Campos ${ }^{I}$ \\ Roberto Carvalho Alves Filho ${ }^{I}$
}

\section{PALAVRAS-CHAVE: \\ - Mudanças no Ensino Médico; \\ - Humanização; \\ - Psicologia Médica; \\ - Educação Médica.}

Recebido em: 17/12/2011

Aprovado em: 04/04/2012

REVISTA BRASLLEIRA DE EDUCAÇÃO MÉDICA

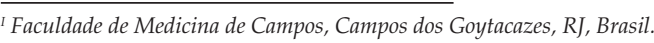

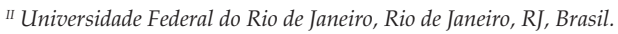

\begin{abstract}
RESUMO
O ensino médico tem sido alvo, nas últimas décadas, de permanente reflexão, mudanças e transformações, principalmente no que tange à revalorização da humanização do ensino e da atividade médica. Inserindo-se no bojo destas discussões e ações, este artigo relata a experiência da inclusão de temas humanísticos no currículo médico que vem ocorrendo na Faculdade de Medicina de Campos/RJ (FMC) desde a década de 1990 e que, avançando neste processo, em 2009 e nos anos subsequentes, implementou a disciplina de Habilidades Médicas, subdividida em módulos. Um deles é o módulo Conversas Médicas, que propõe a reflexão e ampliação da discussão sobre as competências ético-moral, técnica e emocional da atividade médica, esta essencialmente relacional. A implementação da metodologia requereu um esforço interdisciplinar para trabalhar com métodos diversificados com vistas a estabelecer uma relação que transcende o modelo tradicional de ensino. Esta proposta surge das inquietações de profissionais envolvidos na formação médica com o intuito de valorizar os seres humanos envolvidos no cotidiano da atividade médica.
\end{abstract}

\section{ABSTRACT}

The medical school has been the target, in recent decades, of _ permanent reflection, changes and transformations, especially regarding the revaluation of the humanization of education and medical practice. Inserting themselves in the midst of these discussions and actions, this paper aims to report the experience of inclusion of humanistic themes in the medical curriculum that has been occurring in the Medical School of Campos/RJ (FMC) since the 1990s and that advancing in this process in 2009 _ and in subsequent years, implemented the Medical Skills course, sub-divided into modules. One is the module Medical Conversations, which proposes a reflection and extension of the discussion about ethical, moral, technical, and emotional skills of the medical practice, essentially relational. The implementation of the methodology required an interdisciplinary effort to work with diverse methods in order to establish a relationship that transcends the traditional model of education. This proposal arises from the concerns of professionals involved in medical education in order to value the human beings involved in everyday medical practice. 


\section{MUDANÇAS E TRANSFORMAÇÕES EM EDUCAÇÃO MÉDICA: BREVE CONTEXTUALIZAÇÃO}

\begin{abstract}
Do ponto de vista psicológico acontecem mais coisas entre o paciente e o médico do que se lê nos livros-textos.
\end{abstract}

Michel Balint ${ }^{1}$

Por ocasião do $49^{\circ}$ Cobem, cujo tema foi "Educação médica: o desafio de integrar, humanizar e avaliar", observou-se o grande movimento de mudança em torno da formação em Medicina, fortemente impulsionado a partir da década de 1990 pelas discussões da Comissão Interinstitucional Nacional do Ensino Médico (Cinaem). Em síntese, demonstrou-se que "aliar o saber fazer tecnológico ao saber fazer cuidador significa dar à formação médica o encontro resolutivo com as necessidades de saúde, individuais e coletivas, da população brasileira"².

A partir dessa participação, foi possível perceber que o que temos produzido na Faculdade de Medicina de Campos (FMC) se soma a inúmeras iniciativas em todo o Brasil - iniciativas que relevam a importância e pertinência da promoção da saúde mental do acadêmico de Medicina e de ações para somar as noções humanísticas e de cuidado aos conteúdos específicos do campo médico. A composição de uma psicossociopedagogia tem participado da efetivação deste processo com vistas a oferecer aos alunos atenção, cuidado e acolhimento, uma vez que algumas demandas aumentam a preocupação com a saúde mental do médico e do estudante de Medicina, tais como depressão, transtornos de ansiedade, dependência química e suicídio.

O debate sobre a educação médica se intensificou particularmente no Brasil a partir da década de 1980, quando o advento da tecnologia passou a produzir uma formação em Medicina cada vez mais tecnicista e menos humanitária. Este fenômeno, que tem ocorrido nas várias esferas da sociedade, também atingiu as profissões e, em particular, a medicina, alvo de nossa atenção neste trabalho.

Educação médica pode ser definida como "processo de produção de médicos cujo modo escolar se realiza na instituição - a escola médica - com sujeitos, ideologias e culturas peculiares, sob determinadas relações sociais e técnicas" ${ }^{\prime 3}$. O estudo realizado por Feuerwerker ${ }^{3}$ demonstra que os impactos tecnológicos na educação médica têm tido grandes efeitos na prática médica, destacando os campos referentes a humanização, qualidade, integralidade, efetividade e equidade no modelo de atenção.

Assim, têm sido exigidas reformulações em virtude de uma acumulação de problemas que dizem respeito, segundo a autora ${ }^{3}$, a um conjunto de fatores socioacadêmicos que en- volvem, dentre outros, a situação da profissão médica e seu papel social; o processo de acumulação capitalista em saúde; a organização da atenção à saúde (pública e privada); as relações médico-paciente; a universidade e suas relações com os outros segmentos sociais, bem como seu papel na produção, distribuição e consumo de conhecimento, na formação e educação permanente dos profissionais.

Pensa-se numa reformulação que promova um retorno à formação geral diferente da especialização que tem sido a marca da educação médica. Com base nesta proposta, a formação passaria a focalizar a atenção integral e humanizada às pessoas, o trabalho em equipe interdisciplinar, a priorização de uma visão contextual do paciente, para tomar decisões em contraposição a uma visão focal na doença, e a possibilidade de compartilhar o trabalho em saúde.

Neste sentido, um grande avanço foi a homologação das Diretrizes Curriculares Nacionais do Ensino Médico (DCNs) ${ }^{4}$, promulgadas em 2001, como resultado das discussões da Cinaem². As diretrizes preconizam uma formação "generalista, humanista, crítica e reflexiva". Assim, a reflexão sobre o ensino médico se intensificou em torno de questões como as concepções de saúde e doença de uma sociedade, os modelos médicos de saúde e os estilos de pensamento e prática em que se baseiam, as questões sociais e assistenciais, o potencial adoecedor dos ambientes laborais. E é destas reflexões que devem emergir as políticas públicas e as iniciativas socioeducativas para informar e sensibilizar a população, as novas tecnologias e os avanços farmacológicos.

Para uma reorientação efetiva da educação médica, há que se lidar com mudanças profundas que implicam transformação de concepções de saúde, de práticas clínicas e de relações de poder dentro das universidades, dos serviços de saúde e do espaço social ${ }^{5,6}$.

Nas duas últimas décadas do século XX, assistimos a uma grande mudança advinda do campo científico, impulsionada pela revolução microeletrônica e informacional, que atingiu dimensões essenciais da vida humana, como o espaço e o tem$\mathrm{po}^{7}$. Desta realidade emergiu a necessidade premente de conceber uma estrutura curricular que agregue as novas tecnologias à humanização do ensino, na aposta de que isto resulte numa prática mais humanitária em medicina.

Neste sentido, muitos desafios se apresentam, com vista a transformações: necessidade de construir modelos que superem a "lógica unidisciplinar", seguida da adoção de "estratégias inter e transdisciplinares", enquanto "construção de possibilidades de trânsito para campos de conhecimentos 
distintos". Além disso, "a construção de um pensamento complexo, que atua pela busca de interações e interconexões entre conceitos, noções e métodos das várias disciplinas e das relações entre o todo e as partes que um tema específico referende"; bem como a "articulação dos conhecimentos gerados a partir das práticas" 7 .

$\mathrm{O}$ encontro entre psicologia e medicina tem tido um importante papel e originou o campo da psicologia médica, que até a década de 1990 era considerada como estudo da relação médico-paciente. No entanto, a complexidade inerente ao campo provocou um redimensionamento desta concepção, transformando-o em muito mais que uma disciplina. Ele passou a designar um permanente diálogo interdisciplinar sobre questões referentes ao campo médico, o que implica o conceito de saúde e a compreensão do processo saúde-doença em sua dinâmica, as intenções pessoais e tudo que elas envolvem - a relação do médico com o paciente, com a família, com a equipe de saúde, com outros médicos, com a instituição - , bem como sua estruturação psíquica, ou seja, os aspectos constitutivos da personalidade humana que colaboram ou não para facilitar e viabilizar essas relações. Em resumo, visa, sobretudo, constituir o tecido conjuntivo das práticas médicas ${ }^{8}$.

Perestrello ${ }^{9}$, um dos pioneiros, deparou-se em sua prática clínica com a inevitável constatação de que "diagnosticar uma doença é mais que identificar um estado mórbido; é, sobretudo, detectar um modo particular de existir, um existir doente [...] a patologia é, assim, mais que um estudo da doença, é estudo de doentes". Esse médico criou uma concepção de atuação junto à pessoa doente denominada "medicina da pessoa", que se define pela posição de ver "a pessoa, em vez de procurar causas ou fatores, se busca a totalidade", numa "atitude compreensiva" . A partir da concepção desse autor, a psicologia médica ultrapassa a ideia de que o objetivo deste campo é a relação médico-paciente; para além disso, ocupa os "espaços intermediários da assistência".

Parte-se do princípio de que o maior instrumento terapêutico de que o médico dispõe é sua própria pessoa ${ }^{10}$. As implicações desta afirmativa revelam o quão importante é dar atenção a uma formação médica que proporcione, além do desenvolvimento das habilidades técnicas, o trabalho de aspectos subjetivos da pessoa do médico durante a graduação.

Balint ${ }^{1}$ estabelece uma metáfora do médico como remédio e, neste sentido, considera que pouco se sabe sobre uma superdosagem, efeitos colaterais ou secundários, posologia, instruções de como administrar, etc. Isto porque ainda pouco se sabe sobre este tipo de farmacologia de tão importante substância. Daí a necessidade de interação entre os saberes, em especial com a psicologia.
Como aponta Pedrosa ${ }^{11}$, uma das maiores contribuições de Balint é o entendimento de que a pessoa que porta uma doença apresenta "a si mesmo como alguém com uma história que lhe é própria e à qual deveria estar o médico atento para ouvir". Além disso, sempre defendeu a ideia de que "a formação psicológica do médico oportunizaria o desenvolvimento de uma atitude mais sensível às demandas inconscientes que os pacientes trazem às consultas, e que as respostas do médico a esses pacientes, desde que entendidas as demandas, poderiam produzir um efeito terapêutico complementar ao tratamento médico tradicional".

Balint ${ }^{1}$ se interessou por compreender seus colegas médicos e seus pacientes, investigando-os além de suas queixas somáticas. Desenvolveu a concepção de que é o sujeito que pode portar sua doença, mas não bastava investigar os sintomas; era imprescindível entender o sujeito como alguém com uma história própria que deveria ser alvo de atenção do médico. Iniciou seus estudos sobre o médico com o objetivo de compreender em que medida este pode ou não suportar as demandas do paciente e desenvolveu um trabalho na formação médica através da supervisão e discussão de casos com médicos recém-formados.

O cabedal de conhecimentos adquiridos na faculdade
não basta. O médico deve sempre se aprimorar, além de
atualizar-se, mas sabendo sempre que livros, revistas,
congressos e associações de nada valem sem a prática
no consultório ou no hospital. Um ponto de extrema im-
portância é o altruísmo ou o respeito ao paciente ${ }^{12}$ (p.34)

Ao que parece, apesar do avanço tecnológico e da consequente descoberta da cura de várias doenças, sem desprezar outros aspectos importantes da formação médica, a relação médico-paciente tem ocupado a atenção de vários estudos no campo da psicologia médica. Eksterman ${ }^{8}$ menciona que, em mais de 25 anos dedicados ao ensino de psicologia médica, sempre procurou focalizar "a obrigatoriedade do estudante [de Medicina] aprender a lidar com gente, com pessoas, portanto, e não apenas com o funcionamento de uma máquina física chamada corpo". (p.39)

Esse autor defende a inserção de disciplinas como psicologia, antropologia e sociologia médica no currículo médico, assim como a ampliação da carga horária destas a fim de trabalhar no âmbito da formação "e como eixo da prática, o homem doente e não apenas a doença em suas multiformes maneiras de se apresentar"12 (p. 40). O encontro entre o médico e a pessoa em adoecimento é "o substrato indispensável de qualquer ação terapêutica".

Concepções atuais advindas de estudos realizados em torno do campo de saúde, em especial da medicina, demonstram 
que "a doença e o sintoma são estritamente ligados à pessoa doente e exclusivamente a ela", como demonstra Martins ${ }^{13}$. Desse modo, refletir sobre os aspectos psicológicos de quem cuida - a pessoa do médico - torna-se uma necessidade e um imperativo.

Sabemos que diversas iniciativas como esta têm sido desenvolvidas em várias escolas médicas no Brasil. E nossa proposta se inclui entre estas, indo ao encontro do modelo proposto por Eksterman", uma vez que tem "o caráter de uma interdisciplina, ou seja, constituir o tecido conjuntivo das ações em saúde, permeando o estudo da relação médico-paciente em todos os atos médicos e fornecendo o apoio teórico necessário para dar substância científica". (p. 41)

Um programa de psicologia médica, segundo o autor ${ }^{5}$, deve ser norteado pelos seguintes parâmetros:

colaborar para a construção de uma mentalidade médica em detrimento a mera aquisição do conhecimento; comportar-se, no âmbito curricular, como um campo de aprendizagem eminentemente interdisciplinar, presentificando-se nas atividades didáticas de todas as demais disciplinas durante todo o curso; e, por fim, inserir-se no tempo de cada disciplina a partir de programas associados aos objetivos da psicologia médica, obtendo com isso a vantagem de expor ao aluno a óbvia unidade mente-corpo, a qual deve prevalecer em toda ação de saúde. (p.45)

\section{INSERÇÃO DA PSICOLOGIA NOS ESTUDOS MÉDICOS: RELATO DE UMA EXPERIÊNCIA LOCAL}

Um dos espaços de inserção da psicologia foi o campo institucional que se caracteriza como lugar de relações em que as pessoas estão inseridas em torno de um objetivo comum. No caso da FMC, justifica-se pelas múltiplas demandas que emergem destas relações durante o curso e pela necessidade do trabalho preventivo neste âmbito.

O crescente número de estudos sobre a saúde mental dos profissionais de saúde - o que inclui o médico — indica, entre outros dados, que a sobrecarga afetiva proveniente do perfil do trabalho em saúde demanda um cuidado de si mesmo. “O profissional de saúde, no seu cotidiano, vê-se compelido a suportar um conjunto de angústia, de conflitos, de obstáculos diante de cada ato, de cada pessoa com quem se defronta na prática"14 $^{14}$ (p.33).

Esta inserção ocorreu a partir da década de 1990. Compondo a equipe multidisciplinar do Serviço de Apoio ao Educando (SAE), a psicologia esteve presente participando dos diversos projetos oferecidos pela instituição, em atendimentos a alunos, professores e funcionários.

No decorrer dos anos, esse trabalho foi sendo ampliado, e várias ações passaram a ser desenvolvidas paulatinamente, como, por exemplo, entrevistas; atendimentos individuais a familiares de alunos e funcionários; participação nos projetos culturais e técnico-acadêmicos da faculdade (semana científica, semana cultural com mostra de cinema e sarau, discussão do fazer médico através do cinema, mensalmente); participação na elaboração, implantação e execução do Projeto Recepção Solidária, que substituiu o trote vexatório e violento.

Aos poucos, também a psicologia passou a participar de aulas a convite de alguns professores que desejavam abordar e aprofundar a questão da psicologia médica em áreas específicas, tais como Doenças Infectoparasitárias (DIP) e Obstetrícia.

Para estas e outras múltiplas situações e circunstâncias, o trabalho da psicologia na instituição tem se desenvolvido por intermédio de ações, intervenções e atuações, em que se aplicam os conhecimentos adquiridos neste campo com vistas a favorecer o bem-estar dos sujeitos. Veio corroborar também as mudanças curriculares que a instituição tem promovido com uma formação em saúde que prioriza a visão do ser integral, que promove a saúde individual e coletiva com bases mais humanísticas e menos tecnicistas.

Mas, ao invés de constituir uma nova proposta, trata-se da "abordagem médica em sua essência, como um retorno ao ideal hipocrático. Objetiva-se reaproximar o médico do doente, minimizando os efeitos de uma prática distante na cura e reabilitação de pacientes"

Assim, no segundo semestre de 2009, deu-se início à disciplina de Habilidades Médicas no terceiro ano, subdividida em quatro módulos: Laboratório de Habilidades, Habilidades Semiotécnicas, Conversas Médicas e Integração Interdisciplinar. Foge ao objetivo deste artigo tratar da disciplina como um todo. Nosso intento aqui é expor as atividades desenvolvidas no módulo "Conversas Médicas", que destaca e aprofunda aspectos importantes da formação psicológica do médico.

\section{A EXPERIÊNCIA DA DISCIPLINA HABILIDADES MÉDICAS: IMPLEMENTANDO A METODOLOGIA}

A proposta de caráter vivencial vai ao encontro do que é preconizado pelas DCNs, ou seja, que as experiências e inovações não sejam dadas, acabadas e estáticas, mas, sim, que constituam um processo dinâmico e, sobretudo, que se efetivem nas práticas e iniciativas no ensino médico de todo o País.

Trata-se de uma iniciativa que propõe um pensar sobre a medicina como produção de trabalho, tal como formula Schraiber ${ }^{17}$, para além da mera aplicação de conhecimentos. 
Essa autora sustenta que o advento tecnológico do final do século $X X$ trouxe, entre outras, uma consequência direta sobre as interações que o médico estabelece ao efetivar o processo saber-fazer, gerando "rupturas interativas".

Apoia-se ainda no modelo biopsicossocial de saúde, que se apresenta como mais eficaz e apropriado ao enfrentamento das complexas demandas que emergem no campo da saúde e por ser, sobretudo, o modelo preconizado pela OMS. É um modelo que

além de compreender as dimensões física, psicológica e social, proporciona uma visão integral do ser humano e, quando incorporada à formação do médico, aponta para a necessidade de que o profissional mantenha-se num processo constante de formação, para além do aprendizado técnico e do aperfeiçoamento das habilidades instrumentais. As capacidades relacionadas também evoluem e permitem ao médico estabelecer vínculo e comunicação adequados e efetivos(p.106) $)^{18}$

Propostas como esta têm se destacado nas mudanças e transformações curriculares no cenário da educação médica, uma vez que visam inserir e valorizar as dimensões antropológicas, sociais e psicológicas do adoecimento e considerar os aspectos subjetivos presentes nestes contextos e como estes são potencialmente capazes de auxiliar ou prejudicar todo o processo de tratamento do diagnóstico até a reabilitação. "Para que haja uma mudança efetiva desse modelo assistencial, é imprescindível um repensar contínuo da teoria, da prática e das ações em saúde" (p.265) ${ }^{5}$.

A experiência aqui apresentada ainda está em implantação e, por isso, poderia ser questionada quanto a sua viabilidade, eficácia e efetividade como proposta de reformulação educacional da faculdade local. No entanto, entende-se que toda mudança é um processo, e, neste sentido, concordamos com Feuerwerker:

a expectativa quanto à produção de caminhos mais efetivos em relação às mudanças na educação médica é muito grande. A produção de respostas, pistas, indicações, ainda que parciais, provisórias, temporárias, é muito importante e pode ser útil aos muitos outros processos de mudança que se pretende desencadear em todo o país (p.2).

Assim o módulo Conversas Médicas ficou a cargo dos psicólogos e foi subdividido em quatro encontros, como descrito a seguir.

\section{Primeiro Encontro}

O primeiro encontro teve uma proposta introdutória, com a apresentação dos temas que seriam trabalhados no decorrer do semestre: a pessoa do médico como instrumento terapêutico; a clínica da doença $x$ a clínica do doente; modelo biomédico $\mathrm{x}$ modelo biopsicossocial; paradigma da complexidade; da visão dicotômica corpo/mente à concepção do homem como ser biopsicossocial constituído e multideterminado sócio-historicamente; a construção da identidade médica; o campo da saúde como atividade interdisciplinar.

Os principais objetivos deste primeiro módulo foram: possibilitar ao aluno perceber as diferenças entre os modelos biomédico e biopsicossocial; promover um olhar mais abrangente dos quadros de adoecimento, a partir da consideração de outras dimensões (psicológica, antropológica, social); sensibilizar os alunos para o fato de que, na relação médico-paciente, a pessoa do médico é um instrumento terapêutico que viabiliza a adesão do doente ao tratamento; trabalhar o deslocamento do foco do acadêmico da doença para o doente.

\section{Segundo Encontro}

O segundo encontro teve como tema "A formação psicológica do médico", para o que tomamos como base teórica o texto com este título de Eksterman ${ }^{8}$. Destacou a importância desta questão e abordou os conceitos gerais pertinentes ao tema, por meio dos seguintes desdobramentos: constatação a respeito da determinação dos fatores psíquicos nas doenças orgânicas; considerações e conceituação sobre o tripé conhecimentos, habilidades e atitudes; os primórdios da medicina e a subjugação do paciente; etimologia das palavras clínica (klinos, inclinado), patologia (pathos, paixão), ambulatório (ambulare, caminhar), medicamento (medicamen, bruxaria); o binômio médico-paciente e as forças visíveis e invisíveis que norteiam esta relação; a motivação para ser médico; a estrutura psíquica do médico como pessoa: fantasias inconscientes, reparações; conceituações de moral, personalidade, ética, caráter, atributos do eu e identidade; aspectos importantes da relação médico-paciente: regressão, transferência, contratransferência, personalidade do médico; atributos médicos essenciais: esquema referencial (conjunto de conhecimentos, afetos e experiências com os quais o médico pensa, age e se comunica); ação psicoterapêutica do fazer médico; rompimento com a dicotomia corpo-mente; capacidade de intuição e empatia; capacidade de ser continente; capacidade de se deprimir; capacidade de comunicação; sugestões para o trabalho de formação psicológica do médico: atividades clínicas associadas à discussão sobre a atmosfera emocional que envolve o ato médico; trabalho em equipe interdisciplinar; participação em projetos de saúde 
mental; promoção de programas integrativos de educação médica continuada com ênfase em grupos de reflexão.

Os objetivos foram: possibilitar ao aluno refletir sobre a importância da formação psicológica do médico; refletir sobre os elementos norteadores da escolha de ser médico; sensibilizar os alunos para a relevância de conhecer a estrutura do médico enquanto pessoa; identificar pontos fundamentais que sustentam a identidade médica; conhecer os aspectos psicológicos implícitos na relação médico-paciente, tais como: regressão, transferência, contratransferência, conluios inconscientes, tipos de personalidade do médico, entre outros; favorecer a percepção de que a atitude do médico é tão essencial quanto as técnicas e exames utilizados; compreender os atributos essenciais à formação do médico.

Para transpor a visão de uma aula meramente teórica, a equipe propôs realizar um estudo de caso, trazendo um paciente para a sala de aula. Convidamos um paciente oncológico em recuperação, que aceitou prontamente participar. Solicitamos que na sua fala ele enfocasse a importância da atuação médica e da equipe de saúde na sua recuperação, a segurança passada para ele e para a família, a assertividade do diagnóstico, que evitou a má condução do tratamento, entre outros aspectos que julgasse pertinentes, desde a descoberta da doença, o sofrimento do paciente e seus familiares, passando pelo tratamento, atuação do médico e de toda a equipe de saúde, pela hospitalização no Inca, até a recuperação.

\section{Terceiro Encontro}

O terceiro encontro teve como tema "Psicodrama na educação médica: experimentação como metodologia de ensino". Foram abordados os seguintes subtemas: o efeito terapêutico e pedagógico das artes na formação médica; o psicodrama como técnica e ferramenta de sensibilização; a postura do médico diante da dor, sofrimento e morte humanos; os afetos emergentes na relação médico-paciente, de ambas as partes, como possibilidades de trabalhar a formação psicológica do médico; as diferentes perspectivas no trabalho de grupo: linear, sistêmica; a socialização como fundamento da estruturação psíquica e das relações humanas; habilidades sociais nos relacionamentos, com enfoque na relação médico-paciente; comunicação em saúde, a responsabilidade do médico e os direitos do paciente: óbitos, diagnóstico, etc.; o médico diante de difíceis decisões entre a vida e a morte; atributos médicos essenciais: esquema referencial (conjunto de conhecimentos, afetos e experiências com os quais o médico pensa, age e se comunica).

Teve como objetivos: possibilitar ao aluno vivenciar situações do cotidiano do exercício médico por meio da técnica do psicodrama; trabalhar questões da prática médica que en- volvam dor e sofrimento, tais como doenças crônicas, óbitos, óbitos infantis, erro médico; refletir sobre a ética médica nas decisões exigidas do médico no cotidiano do trabalho; favorecer a experimentação e vivências no contexto da formação médica; propiciar a ampliação do autoconhecimento por meio da angústia suscitada por vivências; utilizar o psicodrama como recurso didático-pedagógico; incentivar o exercício da medicina a partir de uma postura crítica e acolhedora da pessoa que o médico atende.

Como recursos didáticos auxiliares para a vivência do psicodrama, foram utilizados alguns elementos para contextualizar a cena - maca, travesseiro, peças de roupas de vestuário - , dando-lhe uma conotação teatral, precedida de tentativas de sensibilização e aquecimento, seguidas da discussão de tudo o que os alunos vivenciaram durante a dramatização.

\section{Quarto Encontro}

A "relação médico-paciente", abordada com auxílio de um estudo de caso, foi o tema do quarto encontro. Este estudo de caso foi trabalhado de duas formas. Num primeiro momento, trabalhamos um caso teórico na área de obstetrícia, juntamente com o professor da área, cujos temas trabalhados foram: Psicologia Aplicada à Obstetrícia: principais fundamentos e conceitos; diferenças nos quadros emocionais nos três semestres gestacionais: primeiro trimestre, ambivalência afetiva; segundo trimestre, oscilação entre estabilidade e fantasias; terceiro trimestre, ansiedade; puerpério como estado de alteração emocional provisória e essencial para que a mãe possa se ligar intensamente ao filho; condições patológicas maternas; o médico diante de intercorrências da gravidez ou do parto em seus aspectos emocionais (abortos provocados ou espontâneos, prematuridade, má-formação fetal); a importância do ambiente do parto em que todos se veem como pessoas: a equipe como facilitadora de um processo natural.

Os objetivos foram: refletir sobre a importância do conhecimento do médico sobre os aspectos psicológicos presentes na gravidez, parto e puerpério; destacar a necessidade de trabalhar a pessoa do médico para que este desenvolva um atendimento voltado para a pessoa e não para a doença, uma atitude indispensável, principalmente, no atendimento à mulher grávida; identificar lacunas no caso clínico que indiquem resistências do médico frente às demandas do paciente; enfocar o objetivo da Psicologia Aplicada à Obstetrícia que é facilitadora do vínculo entre mãe e filho e contribui para reduzir a ansiedade da mulher frente à gestação, ao parto e ao puerpério; discutir as diferenças emocionais nos três trimestres da gravidez, a ambivalência afetiva potencialmente capaz de gerar ansiedade, depressão e pânico, entre outros quadros 
psicopatológicos; ressaltar a importância do ato médico menos tecnicista e mais humanitário no apoio à mulher grávida ou puérpera.

Num segundo momento, trabalhamos a questão utilizando o filme "O escafandro e a borboleta". Trata-se de um filme baseado na história real de um homem bem-sucedido que se torna um paciente crônico após sofrer um AVE hemorrágico predominantemente na região do tronco cerebral, gerando a chamada "síndrome do encarceramento", que o deixa sem nenhum movimento corporal, exceto o da pálpebra do olho direito. Através desse único movimento, ele consegue se comunicar, com a ajuda de uma fonoaudióloga, chegando a escrever um livro, cujo título e conteúdo deram origem ao filme.

Tivemos como temas de discussão: a clínica da reabilitação no âmbito do sistema de saúde (hospitais, clínicas e centros de saúde); atendimento a pacientes crônicos; otimização de serviços prestados por meio do planejamento de pesquisas; atendimento no serviço público e suas implicações para a melhoria da saúde da população em geral, por meio da priorização de uma perspectiva preventiva com foco em grupos vulneráveis e de risco; atuação médica na reabilitação com vistas à emancipação e à mudança social; estratégias de enfrentamento da doença na reabilitação: religiosidade, suporte social ao paciente e seus familiares; mobilização para a adaptação e bem-estar na condição atual do paciente, comunicação familiar, rede de apoio, programa de reabilitação, equipe de reabilitação; o psicólogo na equipe de reabilitação e sua função como facilitador dos relacionamentos e da comunicação individual e grupal; a importância da participação do paciente de reabilitação nas decisões sobre seu tratamento.

Os objetivos estabelecidos foram: destacar a necessidade de trabalhar a pessoa do médico para que este desenvolva um atendimento voltado para a pessoa e não para a doença; identificar lacunas no caso clínico que indiquem resistências do médico frente às demandas do paciente; enfocar o objetivo da psicologia aplicada à reabilitação como facilitadora da recuperação e da redução da ansiedade do paciente frente à sua nova condição de vida; ressaltar a importância do ato médico menos tecnicista e mais humanitário no apoio ao paciente crônico.

\section{REFLEXÃO CRÍTICA SOBRE A PROPOSTA}

A proposta da disciplina foi oferecer uma metodologia diversificada que se apresentasse como alternativa ao modelo tradicional de ensino, para trabalhar questões referentes ao campo da psicologia médica e focalizar importantes aspectos dessa formação que devem ser priorizados.

Neste sentido, foi importante também propor uma forma diferenciada de avaliar esta disciplina curricular. Utilizamos uma forma de avaliação continuada, que proporcionou aos alunos, no final de cada encontro, a possibilidade de falar sobre sua participação, sobre a metodologia adotada pelos professores e sobre o conteúdo exposto, entre outros pontos abordados em seus aspectos positivos e negativos, bem como uma avaliação anônima e por escrito no final do semestre. Também lançamos mão de um trabalho escrito individual com uma questão aberta em que os alunos expuseram individualmente seu aproveitamento em relação ao que foi trabalhado a cada dia.

Fazer dos encontros uma experiência de vida horizontal, buscando quebrar a hierarquia verticalizada, foi sempre um dos principais alvos da equipe, uma vez que, via identificação, a atitude vertical nos relacionamentos acaba por contaminar o estudante de Medicina, levando-o a reproduzir e perpetuar na relação médico-paciente a postura fria e distante na relação entre professor e aluno.

A reação dos alunos à implementação da disciplina foi diversificada. Alguns esperavam que a disciplina fosse prática em sua totalidade, passando todo o tempo de aula no laboratório:

\footnotetext{
"Não é que o que vocês estão falando não seja importante, não, mas a gente vive esperando pela prática. Sei lá, queria estar no laboratório agora".
}

Outros apresentaram resistência ao novo, uma vez que, até então, não tinham trabalhado com as técnicas que utilizamos - uma reação, em grande medida, esperada pela equipe:

"É estranho ter que acender fósforos e ficar fazendo um teatro, acho que não dou para isso, não, meu lance é medicina".

Mas, em sua maioria, os alunos têm tido boa receptividade à proposta e à forma como ela tem sido trabalhada:

"Aqui na faculdade, a gente passa muito tempo 'comendo' livro; chega uma hora em que a gente precisa parar e pensar sobre o que estamos fazendo, refletir mesmo, até para ver onde isso vai dar".

A equipe tem ouvido criteriosamente estas avaliações, considerando diferentes aspectos da realidade da formação que os alunos estão recebendo, e proposto as devidas reformulações.

Um ponto que tem chamado a atenção da equipe é o interesse pela bibliografia comentada em aula, pois alguns alunos nos procuraram após as aulas para saber mais sobre os livros que utilizamos e mencionamos durante os encontros. Alguns 
compraram os livros que recomendamos e também tomaram alguns por empréstimo.

"Achei muito interessante este comentário sobre as decisões
do médico, gostaria de ler sobre o assunto, são situações que
nunca tinha parado para pensar".

Esta fala de um aluno se refere à publicação de Menezes ${ }^{19}$.

Também obtivemos alguns comentários positivos sobre a metodologia com que trabalhamos, a dinâmica de acolhida no primeiro encontro, o estudo de caso clínico, o psicodrama.

"No início achei que seria só um teatro chato, mas depois foi muito legal, eu me vi ali na situação... e o pior: sem saber o que fazer"

São atividades com propostas bem diferentes de tudo o que eles experimentam no cotidiano da faculdade, marcado por ambientes ambulatoriais e hospitalares em que predominam doenças, dores, sofrimentos, óbitos, que acabam por ofuscar, diante da urgência, o olhar para o humano que sofre, sente, se emociona - enfim, ambientes afetados pela doença, pelo sofrimento e, em última análise, pela morte.

Um aspecto interessante é que alguns dos temas que trabalhamos nos módulos - tais como a relação médico-paciente e o médico diante da morte - despertaram a atenção dos alunos, que mencionaram querer estudá-los mais em outros momentos, por julgá-los de grande importância na formação do médico.

"Vocês estão me perguntando se eu imagino qual a minha reação diante da morte de um paciente; mas como eu vou saber se eu não estudei sobre isso?".

Este fato tem reafirmado nossa intenção de continuar pensando neste trânsito da psicologia médica pelo currículo e intensificar as discussões sobre a relevância e pertinência de implementar um programa de psicologia médica durante todo o curso de Medicina.

Relevante também é o trabalho preventivo que ocorre ao sensibilizarmos o aluno. Com isto, suas emoções surgem, oferecendo subsídios a uma intervenção antes que ocorra o agravamento de determinadas situações ou mesmo seu surgimento.

\section{CONSIDERAÇÕES FINAIS}

Em muitos sentidos, a disciplina é considerada inovadora. Sabemos que o investimento na psicologia e na interdisciplinaridade nesta disciplina visa, sobretudo, minimizar os efeitos da formação biomédica que separa por demais o médico do doente e dele mesmo.

As experiências com a inserção da psicologia ao longo do currículo e não apenas se restringindo à carga horária reservada à disciplina são iniciativas que tendem a se ampliar graças aos efeitos positivos obtidos.

Este é o momento atual, de mudanças e reformulações. Encontramos uma expressão do que sentimos neste momento na seguinte frase: "Grupos e pessoas estão sob a mira de um desafio: ou experimentam voos de águias ou se contentam com o conservadorismo que corrói a energia das instituições" ${ }^{\prime 7}$. Ficamos com a primeira opção!

\section{REFERÊNCIAS}

1. Balint M. O médico, seu paciente e a doença. $2^{\underline{a}}$ ed. São Paulo: Ed. Atheneu; 2007.

2. Merhy EE, Aciole GG. Uma nova escola médica é possível? Aprendendo com a CINAEM as possibilidades de construção de novos paradigmas para a formação em medicina. Pro-Posições. 2003;14(1).

3. Feuerwerker LCM. Além do discurso de mudanças na educação médica: processos e resultados. São Paulo: Hucitec; 2002.

4. Brasil. Diretrizes Curriculares Nacionais para os Cursos de Medicina. Ministério de Educação e Cultura. 2001.

5. Nogueira MI. As mudanças na educação médica brasileira em perspectiva: reflexões sobre a emergência de um novo estilo de pensamento. [on-line] Rev Bras Educ Méd (no prelo). [Capturado em 15 de julho de 2011]. Disponível em http:/ / www.educacaomedica.org.br.

6. Alves Filho RC. O corpo na/da Psicanálise: primeiros escritos. Trabalho de Conclusão de Curso em Pós-Graduação em Teoria e Clínica Psicanalítica, Universidade Gama Filho/RJ. 2008.

7. Minayo MCS. O desafio do conhecimento: pesquisa qualitativa em saúde. $11^{\circ}$ ed. São Paulo: Hucitec; 2008.

8. Eksterman A. O ensino de psicologia médica. In: Mello Filho J, org. Identidade Médica. São Paulo: Casa do Psicólogo; 2006. p. 39-58.

9. Perestrello D. A Medicina da Pessoa. $4^{\text {a }}$ Ed. Rio de Janeiro: Atheneu; 1996.

10. Mello Filho J, org. Psicossomática Hoje. Porto Alegre: Artes Médicas; 1992.

11. Pedrosa MAL. Reflexões sobre Michel Balint: comunicando uma experiência de grupo. In: Mello Filho J. Psicossomática Hoje. Porto Alegre: Artes Médicas Sul; 1992. p. 152-159.

12. Mello Filho J, org. Identidade Médica. São Paulo: Casa do Psicólogo; 2006. 
13. Martins PH. Contra a desumanização da medicina: crítica sociológica as práticas médicas modernas. Petrópolis/RJ: Vozes Ed; 2003.

14. Campos EP. Quem cuida do cuidador: uma proposta para os profissionais de saúde. $2^{\underline{a}}$ ed. Petrópolis/RJ: Vozes Ed; 2005.

15. Mello DRB. Nos limites da linguagem: um estudo das doenças psicossomáticas à luz da psicanálise lacaniana. Rio de Janeiro; 2007. Mestrado [Dissertação] - Programa de Pós-graduação em Cognição e Linguagem, UENF/RJ.

16. Pinheiro R. Escolha e abandono de médicos: o poder do cliente. Salvador/BA: Raimundo Pinheiro Consultoria Ed; 2002.

17. Schraiber LB. O médico e suas interações: a crise dos vínculos de confiança. São Paulo: Aderaldo e Rotlschild; 2008.

18. Mello DRB. Violência e a inclusão deste tema nos currículos médicos: breves reflexões. Rev Perspectiva [on-line]. 2010; 4(16). Disponível em http:/ / seer.perspectivasonline.com.br.

19. Menezes RA. Difíceis decisões: etnografia de um Centro de Tratamento Intensivo. Rio de Janeiro: Ed Fiocruz; 2006. $107 \mathrm{p}$.

\section{CONTRIBUIÇÃO DOS AUTORES}

Denise R. B. Mello participou da análise e interpretação dos dados, assim como da elaboração do texto, revisão final. Lígia C. Leite participou da análise e interpretação dos dados, assim como da elaboração do texto discutindo a experiência realizada e de sua revisão final. Maria das Graças S. C. e Campos participou da análise e interpretação dos dados, assim como da elaboração do texto, revisão final. Roberto Carvalho A. Filho participou da análise e interpretação dos dados,, na execução da experiência, de seu relato, assim como da elaboração do texto e sua revisão final.

\section{CONFLITO DE INTERESSES}

Declarou não haver.

\section{ENDEREÇO PARA CORRESPONDÊNCIA}

Denise Ribeiro Barreto Mello

Rua São Bartolomeu, 149

Caju - Campos dos Ggoytacazes

CEP. 28051-060 RJ

E-mail: deniserbmello@gmail.com 